\title{
The National Neurosurgery Quality and Outcomes Database Qualified Clinical Data Registry: 2015 measure specifications and rationale
}

\author{
Scott L. Parker, MD, ${ }^{1}$ Matthew J. McGirt, MD, ${ }^{2}$ Kimon Bekelis, MD, ${ }^{3}$ \\ Christopher M. Holland, MD, PhD, ${ }^{4}$ Jason Davies, MD, PhD, ${ }^{5}$ Clinton J. Devin, MD, ${ }^{6}$ \\ Tyler Atkins, MD, ${ }^{2}$ Jack Knightly, MD, ${ }^{7}$ Rachel Groman, MPH, ${ }^{8}$ Irene Zyung, BA, ${ }^{9}$ and \\ Anthony L. Asher, MD²
}

\begin{abstract}
Departments of ${ }^{1}$ Neurological Surgery and ${ }^{6}$ Orthopaedic Surgery, Vanderbilt University Medical Center, Nashville, Tennessee; 2Department of Neurosurgery, Carolina Neurosurgery \& Spine Associates and Neuroscience Institute, Carolinas Healthcare System, Charlotte, North Carolina; ${ }^{3}$ Section of Neurosurgery, Dartmouth-Hitchcock Medical Center, Lebanon, New Hampshire; ${ }^{4}$ Department of Neurosurgery, University of Utah, Salt Lake City, Utah; ${ }^{5}$ Department of Neurological Surgery, State University of New York at Buffalo, New York; ${ }^{7}$ Department of Neurological Surgery, Atlantic Neurosurgical Specialists, Morristown, New Jersey; ${ }^{8}$ Clinical Affairs and Quality Improvement, Hart Health Strategies, Washington, DC; and ${ }^{9}$ American Association of Neurological Surgeons, Rolling Meadows, Illinois
\end{abstract}

\begin{abstract}
Meaningful quality measurement and public reporting have the potential to facilitate targeted outcome improvement, practice-based learning, shared decision making, and effective resource utilization. Recent developments in national quality reporting programs, such as the Centers for Medicare \& Medicaid Services Qualified Clinical Data Registry (QCDR) reporting option, have enhanced the ability of specialty groups to develop relevant quality measures of the care they deliver. QCDRs will complete the collection and submission of Physician Quality Reporting System (PQRS) quality measures data on behalf of individual eligible professionals. The National Neurosurgery Quality and Outcomes Database (N²QD) offers 21 non-PQRS measures, initially focused on spine procedures, which are the first specialtyspecific measures for neurosurgery. Securing QCDR status for $N^{2} Q O D$ is a tremendously important accomplishment for our specialty. This program will ensure that data collected through our registries and used for PQRS is meaningful for neurosurgeons, related spine care practitioners, their patients, and other stakeholders. The $2015 \mathrm{~N}^{2} \mathrm{QOD}$ QCDR is further evidence of neurosurgery's commitment to substantively advancing the health care quality paradigm. The following manuscript outlines the measures now approved for use in the $2015 \mathrm{~N}^{2} \mathrm{QOD}$ QCDR. Measure specifications (measure type and descriptions, related measures, if any, as well as relevant National Quality Strategy domain[s]) along with rationale are provided for each measure.
\end{abstract}

http://thejns.org/doi/abs/10.3171/2015.9.FOCUS15355

KEY WORDS N2QOD; registry; qualified clinical data registry; Physician Quality Reporting System

$\mathrm{M}$ EANINGFUL quality measurement and public reporting has the potential to facilitate targeted outcome improvement, practice-based learning, shared decision-making, and effective resource utilization..$^{140}$ Regrettably, regulatory and economic pressures have created a complex network of quality requirements for physicians and practice groups. These include the Centers for Medicare \& Medicaid Services (CMS) Physician
Quality Reporting System (PQRS), the CMS Electronic Health Records (EHR) Incentive Program (more commonly referred to as Meaningful Use [MU]), and the CMS Value-Based Payment Modifier (VM) program. The common denominator of these initiatives is that to avoid penalties, physicians must meet "generic" quality standards, which in the case of neurosurgery and many other medical specialties, are not pertinent to everyday clinical practice.

ABBREVIATIONS ACS NSQIP = American College of Surgeons National Surgical Quality Improvement Program; BMI = body mass index; CMS = Centers for Medicare \& Medicaid Services; CVA = cerebrovascular accident; DVT = deep venous thrombosis; EP = eligible professional; MI = myocardial infarction; NPA = NeuroPoint Alliance; $\mathrm{N}^{2} \mathrm{QOD}=$ National Neurosurgery Quality and Outcomes Database; NQS = National Quality Strategy; PE = pulmonary embolism; PQRS = Physician Quality Reporting System; QCDR = Qualified Clinical Data Registry; SSI = surgical-site infection; UTI = urinary tract infection.

SUBMITTED July 22, 2015. ACCEPTED September 18, 2015.

INCLUDE WHEN CITING DOI: 10.3171/2015.9.FOCUS15355. 
Fortunately, recent developments in national quality reporting programs, such as the CMS Qualified Clinical Data Registry (QCDR) reporting option, have significantly enhanced and streamlined the ability of specialty groups to develop and report relevant measures of health care quality. The QCDR reporting mechanism was introduced for the Physician Quality Reporting System (PQRS) in 2014. A QCDR is a CMS-approved entity that collects medical and/or clinical data for the purpose of patient and disease tracking to foster improvement in the quality of care provided to patients. A QCDR completes the collection and submission of PQRS quality-measures data on behalf of individual eligible professionals (EPs). Individual EPs who satisfactorily participate in the 2015 PQRS through a QCDR may avoid the 2017 negative payment adjustment $(-2.0 \%)$. A QCDR is different from a CMS qualified registry in that it is not limited to measures within PQRS, but rather it allows for specialty societies and other groups to develop novel measures that are relevant. To be considered a QCDR for purposes of PQRS, an entity must self-nominate and successfully complete a qualification process. These programs amplify the power of clinical registries, leveraging the specialty's efforts to accurately document care, patient experiences, and outcomes, and to use these to define and demonstrate value as it relates to the specialty.

In November 2014, the NeuroPoint Alliance (NPA), a 501-c6 organization established by the American Association of Neurological Surgeons to collect, analyze, and report on nationwide clinical data from neurosurgical practices using online technologies, began the process of developing quality measures specific to the practice of neurological surgery. A multidisciplinary team comprising health care policy experts, clinician-scientists, quality scientists, medical administrators, and epidemiologists surveyed exiting PQRS-approved measures, examined the performance of various measures used in our existing registry projects (such as the National Neurosurgery Quality and Outcomes Database [ $\left.\mathrm{N}^{2} \mathrm{QOD}\right]$ ) and outlined gaps in existing quality reporting related to neurosurgical diseases. With treatment of spinal disorders accounting for almost $70 \%$ of neurosurgical care, the NPA determined this to be neurosurgery's greatest short-term opportunity in measure development. Furthermore, the treatment of degenerative spine disease has been identified by many health care stakeholders as a target area for improving health care value due to the high cost and rapidly expanding application of spinal therapies. ${ }^{36,152}$

In January 2015, the NPA submitted 21 preliminary measures to CMS for provisional approval. Initial approval was granted, and from February through March 2015, these measures underwent further internal review (NPA) and external review (CMS contractors) prior to final submission. On March 31, 2014, 21 non-PQRS (i.e., novel) measures were submitted to CMS along with a data validation plan. On April 2, 2015, the $\mathrm{N}^{2} \mathrm{QOD}$ became an approved QCDR in the PQRS for the 2015 program year.

The $\mathrm{N}^{2} \mathrm{QOD}$ QCDR offers 21 non-PQRS measures, initially focused on spine procedures, which are the first specialty-specific measures for neurosurgery. Securing QCDR status for $\mathrm{N}^{2} \mathrm{QOD}$ is a tremendously important accomplishment for our specialty. This program will ensure that data collected through our registries and used for PQRS is meaningful for neurosurgeons, related spinecare practitioners, their patients and other stakeholders. The $2015 \mathrm{~N}^{2}$ QOD QCDR is further evidence of neurosurgery's commitment to substantively advancing the health care quality paradigm.

The $\mathrm{N}^{2} \mathrm{QOD}$ is designed to address the need for highquality outcomes data related to care of patients with neurosurgical and spine disorders. $\mathrm{N}^{2} \mathrm{QOD}$ provides United States surgeons, practice groups, and hospital systems the ability to comprehensively analyze and report on the quality of their care. Analyses of data collected through the $\mathrm{N}^{2} \mathrm{QOD}$ have already helped demonstrate the effectiveness of neurosurgical care and identify important care improvement opportunities. ${ }^{104}$

\section{Participating in the N2QOD QCDR}

The $\mathrm{N}^{2} \mathrm{QOD}$ QCDR is open to all participating $\mathrm{N}^{2} \mathrm{QOD}$ registry physicians. Eligible professionals (EPs) interested in participating in the $\mathrm{N}^{2} \mathrm{QOD}$ QCDR who are not currently participating in the registry can enroll by completing the steps for $\mathrm{N}^{2} \mathrm{QOD}$ participation listed on the NPA website. ${ }^{2}$ These steps include review of the $\mathrm{N}^{2} \mathrm{QOD}$ program by the local institutional review board or quality improvement office, completing participation, business associate, and data use agreements, and completing $\mathrm{N}^{2} \mathrm{QOD}$ registration and training.

Once enrolled in the $\mathrm{N}^{2} \mathrm{QOD}$ registry, EPs and groups can sign up and participate in the $\mathrm{N}^{2} \mathrm{QOD}$ QCDR through the NPA-QCDR registration process. Registration includes completion of the NPA-QCDR Provider Consent Form and NPA Data Use Addendum, which authorize NPA to submit PQRS data to CMS on the EP's behalf. The Provider Consent Form requires each EP to provide his or her Tax Identification Number (TIN) and National Provider Identification (NPI) number and to attest to their Medicare eligibility and that the TIN/NPI numbers are correct. The NPA Data Use Addendum specifies the terms of QCDR participation through the $\mathrm{N}^{2} \mathrm{QOD}$ QCDR, data submission, public reporting of QCDR data, audit and data validation requirements, and the process for notifying CMS if inaccuracies are found in the CMS submission.

Additionally, EPs must fill out the registration forms in the $\mathrm{N}^{2} \mathrm{QOD}$ QCDR module indicating their scope of participation (lumbar only, cervical only, or both lumbar and cervical), and confirming their selected QCDR measures for reporting. For 2015, individual EPs using a QCDR to satisfy PQRS reporting requirements must submit data on at least 9 measures across at least 3 National Quality Strategy (NQS) domains and include 2 outcome measures. The $\mathrm{N}^{2} \mathrm{QOD}$ QCDR offers a set of 9 Core Measures that meet these QCDR requirements and is already embedded within the $\mathrm{N}^{2} \mathrm{QOD}$ spine modules. EPs and groups have the option of substituting a measure within the core or including more than the minimum 9 measures.

Following registration in the $\mathrm{N}^{2} \mathrm{QOD}$ QCDR, EPs and centers will need to complete $\mathrm{N}^{2} \mathrm{QOD}$ QCDR training which details patient enrollment, measures selection, performance rate scoring, audits, as well as interim and final 
surgeon reporting. EPs can begin entering their PQRS data in the $\mathrm{N}^{2} \mathrm{QOD}$ QCDR after training has been conducted. On a monthly basis, EPs will receive interim feedback reports tracking their progress for meeting the PQRS measures. A final report is provided to EPs at the end of the reporting period.

Although this paper focuses on the 2015 PQRS program, which allows for individual reporting under QCDR, beginning in 2016, physicians will be able to use QCDR reporting at both the individual and group level. More details of the group reporting option will be made available on the NPA website in late 2015.

It is important for neurosurgeons to note the following reporting differences between "standard" $\mathrm{N}^{2} \mathrm{QOD}$ registry participation, and participation in the $\mathrm{N}^{2} \mathrm{QOD}$ with the QCDR option.

1) $N^{2} Q O D$ participants currently provide clinical data using a sampling methodology. Sampling methodologies can be quite powerful and yield accurate, representative results when properly applied. Briefly, the first 6 eligible patients per week meeting enrollment criteria and scheduled to undergo lumbar/cervical spine surgery are identified. Once 6 patients have answered the baseline questionnaires and they have undergone their surgery, the target has been reached and no additional patients are required for enrollment in the registry. A rotating 6-day cycle is used to ensure that enrollment will not always commence on the same operative weekdays. This method allows for a representative sampling of patient experiences from the individual sites and has been employed by other national registry projects.

2) In contrast, the CMS QCDR reporting requirements require data capture from $50 \%$ of all relevant patients. In the context of the $\mathrm{N}^{2} \mathrm{QOD}$, this would include $50 \%$ of all eligible patients as defined by the registry inclusion/ exclusion criteria. Therefore, depending on the case composition for each individual practitioner or practice group, QCDR participation in the context of the $\mathrm{N}^{2} \mathrm{QOD}$ may result in an increased reporting burden compared with that required in the registry alone.

As the QCDR is approved for use by CMS as a "standalone" $\mathrm{PQRS}$ vehicle, it is likely that participation in this program will ultimately be made available to non- $\mathrm{N}^{2} \mathrm{QOD}$ participating EPs. Use of the QCDR independent of the standard registry may allow individuals/groups with limited resources and a focused desire to satisfy PQRS requirements (as opposed to broader registry goals such as targeted quality improvement) at a reduced reporting burden.

However, it should also be noted that the NPA is noticing a trend among many groups to increase their data reporting beyond that required by the sampling methodology. In fact, at least 4 centers are in the process of transitioning to $100 \%$ capture of all eligible patients. Total data capture, which is employed by other national registry programs including the Society of Thoracic Surgeons National Database, reduces error related to imperfections in the sampling process and allows for a more comprehensive approach to quality assessment/improvement. More complete data capture is also being facilitated by a variety of novel technologies and methods now being developed by NPA in cooperation with other groups. Furthermore, it is highly likely that private groups will ultimately adopt quality data standards consistent with those promoted by CMS. In this respect, $\mathrm{N}^{2} \mathrm{QOD}$ participants who use the $\mathrm{N}^{2} \mathrm{QOD}$ QCDR option may be preparing themselves to successfully navigate emerging trends in quality reporting, which will unquestionably include 1) more relevant, specialty specific measures and 2) more complete capture of relevant patient data.

Neurosurgeons at 10 clinical centers have enrolled in the $\mathrm{N}^{2} \mathrm{QOD}$ QCDR to date, with approximately 40 surgeons anticipated for the 2015 program year. More information is available on the NPA website: http://www.neuropoint. org/NPA\%20N2QOD\%20Physician\%20Quality\%20 Reporting\%20System.html.

\section{The $2015 \mathrm{~N}^{2} \mathrm{QOD}$ Measures}

The following section outlines the individual measures now approved for use in the $2015 \mathrm{~N}^{2} \mathrm{QOD}$ QCDR. Measure specifications (related measures, if any, relevant National Quality Strategy [NQS] domain[s], measure type, and descriptions) along with rationale are provided in each individual descriptions. Appendix 1 contains the denominator exclusions and exceptions for all 21 measures.

\section{N2QOD Spine Care Measure 1: Spine Pain Assessment}

NQS Domain: Person and Caregiver-Centered Experience Outcomes

PQRS No./NQF No.: Non-PQRS; PQRS 131, NQF 420, and modification of PQRS 109

\section{Measure Type (Process/Outcome): Outcome}

Description: Percentage of patients aged 18 years and older with documentation of a pain assessment through discussion with the patient including the use of a standardized back or neck pain tool(s) at baseline and 3 months following index therapy for treatment of spine-related pain symptoms and documentation of follow-up plan.

Denominator: $\mathrm{N}^{2} \mathrm{QOD}$ QCDR patients, See Appendix 1

Numerator: Number of patients aged 18 years and older with documentation of a pain assessment through discussion with the patient including the use of a standardized back or neck pain tool(s) at baseline and 3 months following index therapy for treatment of spine-related pain symptoms and documentation of follow-up plan.

\section{Rationale}

Spine-related pain is a highly prevalent and disabling condition. Approximately one-quarter of adults in the United States reported at least 1 full day of low-back pain over a 3-month span, and low-back pain accounts for $2.3 \%-2.8 \%$ of all physician visits. Low-back pain alone represents the most expensive cause of work-related disability in the United States. ${ }^{35}$ A recent analysis of 4970 patients enrolled in the $\mathrm{N}^{2} \mathrm{QOD}$ Spine Registry found significant levels of baseline spine pain in patients scheduled to undergo elective spine surgery (average pain score 6.5 on a scale of 1-10). ${ }^{9}$ Significant improvements in back pain have been reported following surgery for a variety of lumbar spine conditions. ${ }^{103,106-108,122}$ Further, these stud- 
ies have established the minimum clinically important change in back pain scores following surgery, representing a threshold to distinguish meaningful patient improvements. ${ }^{103,106-108,122}$ Given the prevalence and debilitating nature of spine-related pain, accurate assessment of patients' spine discomfort before and after therapy is essential to assess the impact of interventions and make appropriate plans for continuing care.

\section{$\mathrm{N}^{2}$ QOD Spine Care Measure 2: Extremity (Radicular) Pain Assessment}

NQS Domain: Person and Caregiver-Centered Experience Outcomes

PQRS No./NQF No.: Non-PQRS; PQRS 131, modification of PQRS 109

\section{Measure Type (Process/Outcome): Outcome}

Description: Percentage of patients aged 18 years and older with documentation of a pain assessment through discussion with the patient including the use of a standardized leg or arm pain tool(s) at baseline and 3 months following index therapy for treatment of spine-related pain symptoms and documentation of follow-up plan.

Denominator: N²QOD QCDR patients, See Appendix 1

Numerator: Number of patients aged 18 years and older with documentation of a pain assessment through discussion with the patient including the use of a standardized leg or arm pain tool(s) at baseline and 3 months following index therapy for treatment of spine related pain symptoms and documentation of follow-up plan.

\section{Rationale}

Extremity pain related to spinal disorders (i.e., radicular pain) is a highly prevalent and disabling condition. Lumbosacral radicular pain alone has been estimated to have an annual prevalence of $10 \%-25 \%$ in the general population. ${ }^{148} \mathrm{~A}$ recent analysis of 4970 patients enrolled in the $\mathrm{N}^{2} \mathrm{QOD}$ Spine Registry found significant levels of patient-reported baseline radicular pain in patients scheduled to undergo elective spine surgery (average pain score 6.9 on a scale of 1-10). ${ }^{9}$ Significant improvements in radicular pain have been reported following surgery for a variety of lumbar spine conditions. ${ }^{103,106-108,122}$ Further, these studies have established the minimum clinically important change in radicular pain scores following surgery, representing a threshold to distinguish meaningful patient improvements. ${ }^{103,106-108,122}$ Given the prevalence and debilitating nature of radicular pain, accurate assessment before and after therapy is essential to assess the impact of interventions and make appropriate plans for continuing care.

\section{N2QOD Spine Care Measure 3: Functional Outcome Assessment for Spine Intervention}

NQS Domain: Person and Caregiver-Centered Experience Outcomes

PQRS No./NQF No.: Non-PQRS; PQRS 220, PQRS 223, PQRS 182, PQRS 109, PQRS 217, PQRS 218, PQRS219 and NQF 0422, 0423, and 0424 modification

Measure Type (Process/Outcome): Outcome
Description: Percentage of patients aged 18 years and older undergoing index spine therapy (s) who completed baseline and 3-month follow-up (patient-reported) functional outcome assessment.

Denominator: N²QOD QCDR patients, See Appendix 1

Numerator: Number of patients aged 18 years and older undergoing index spine therapy (s) who completed baseline and 3-month follow-up (patient-reported) functional outcome assessment.

\section{Rationale}

Degenerative spine disease is recognized as a leading cause of disability in society, ${ }^{135}$ and low-back pain is the most expensive cause of work-related disability in the United States. ${ }^{35}$ Measures of spine-related patient disability have been established and validated..$^{39}$ A recent analysis of 4970 patients enrolled in the $\mathrm{N}^{2} \mathrm{QOD}$ Spine Registry found significant levels of patient-reported baseline functional impairment in patients scheduled to undergo elective spine surgery (average disability index 50 [severe disability]). ${ }^{9}$ Improvements in disability scores following spine surgery have been demonstrated in a number of conditions. ${ }^{102,106-108,122,150,151}$ One multicenter study investigated the outcomes of treatment for lumbar spinal stenosis, which represents the most common indication for surgery in patients over 65 years old. ${ }^{151} \mathrm{In}$ an as-treated analysis of 654 patients with 4-year follow-up, functional disability was found to be significantly reduced in patients who underwent surgery compared to those treated without surgery. ${ }^{151}$ Given the prevalence, socioeconomic impact, and relative severity of spine-related functional impairment, accurate assessment of patients' functional status before and after therapy is essential to assess the impact of interventions and make appropriate plans for continuing care.

\section{N2QOD Spine Care Measure 4: Quality-of-Life Assessment for Spine Intervention}

NQS Domain: Person and Caregiver-Centered Experience Outcomes

\section{PQRS No./NQF No.: Non-PQRS}

Measure Type (Process/Outcome): Outcome

Description: Percentage of patients aged 18 years and older undergoing index spine therapy(-ies) who completed baseline and 3-month follow-up (patient-reported) quality-of-life assessment.

Denominator: $\mathrm{N}^{2} \mathrm{QOD}$ QCDR patients, See Appendix 1

Numerator: Number of patients aged 18 years and older undergoing index spine therapy(-ies) who completed baseline and 3-month follow-up (patient-reported) quality-of-life assessment.

\section{Rationale}

Patient-reported quality of life is increasingly recognized as an important tool to allow clinicians to assess the effectiveness of various therapies, particularly when combined with traditional clinical measures of health. ${ }^{46,92}$ Impaired quality of life is commonly caused by spinal disorders, and routine use of quality-of-life instruments along with other patient-reported outcomes tools has been 
recommended in association with spine therapies. ${ }^{26,33} \mathrm{~A}$ recent analysis of 4970 patients enrolled in the $\mathrm{N}^{2} \mathrm{QOD}$ Spine Registry found significantly diminished levels of baseline patient-reported quality of life (average baseline EQ-5D score 0.54 on a scale of $0-1$, where 0 is the worst) in patients scheduled to undergo elective spine surgery. ${ }^{9}$ Improvements in quality-of-life measures following spine surgery have been demonstrated in a number of conditions. ${ }^{103,106-108,122,150,151}$ One multicenter study investigated the outcomes of treatment for lumbar spinal stenosis, which represents the most common indication for surgery in patients over 65 years old. ${ }^{151}$ In an as-treated analysis of 654 patients with 4-year follow-up, quality of life was found to be significantly improved in patients who underwent surgery compared to those treated without surgery. ${ }^{151}$ Given the prevalence, and relative severity of spine-related impairment of quality of life, accurate assessment of patients' self-reported quality of life before and after therapy is essential to assess the impact of interventions and make appropriate plans for continuing care.

\section{$N^{2}$ QOD Spine Care Measure 5: Patient Satisfaction With Spine Care}

NQS Domain: Person and Caregiver-Centered Experience Outcomes

PQRS No./NQF No.: Non-PQRS; modification of PQRS 304

\section{Measure Type (Process/Outcome): Outcome}

Description: Percentage of patients aged 18 years and older undergoing index spine therapy (s) who completed 3 -month follow-up (patient-reported) satisfaction with care assessment.

Denominator: $\mathrm{N}^{2} \mathrm{QOD}$ QCDR patients, See Appendix 1

Numerator: Number of patients aged 18 years and older undergoing index spine therapy(-ies) who completed 3 -month follow-up (patient-reported) satisfaction with care assessment.

\section{Rationale}

Patient satisfaction represents a subjective assessment of a patient's overall health care experience, and it has emerged as a common outcome measure following spine surgery. ${ }^{28}$ In part due to its ease of assessment, both health care organizations and third-party payers have used patient satisfaction as a proxy for quality of care..$^{28,47}$ Further, the Joint Commission on Accreditation of Healthcare Organizations has identified patient satisfaction as an important measure and suggests that it be used for accreditation purposes. ${ }^{49} \mathrm{~A}$ recent analysis of 4970 patients enrolled in the $\mathrm{N}^{2} \mathrm{QOD}$ Spine Registry found significant improvements in patient-reported satisfaction after elective spine surgery, although almost $20 \%$ of patients reported less than satisfactory experiences. ${ }^{9}$ While there is some evidence that patient satisfaction may not be a valid means of assessing quality health care ${ }^{47}$ other studies have found positive correlations between patient satisfaction and measures of pain and disability. ${ }^{157,158}$ Given the increased interest in patient satisfaction, studies have more recently sought to determine what factors contribute to these scores. At least
2 such studies have now found that 1 important factor in improving patient satisfaction following surgery is accurately establishing realistic patient expectations prior to surgery. ${ }^{117,138}$ Given the increasing relevance of satisfaction metrics in advancing patient-centered measures of health care services, along with improvement opportunities identified in a large national clinical data program, accurate assessment of patients' self-reported satisfaction with care before and after therapy is essential to assess the impact of interventions and make appropriate plans for continuing individual care as well as to improve the systemic aspects of care.

\section{$N^{2}$ QOD Spine Care Measure 6: Spine-Related Procedure Site Infection}

NQS Domain: Effective Clinical Care

PQRS No./NQF No.: Non-PQRS; NQF 0130, PQRS 357, modification of PQRS 165

\section{Measure Type (Process/Outcome): Outcome}

Description: Percentage of patients aged 18 years and older who had a surgical-site infection (SSI) within 30 days of the index spine procedure.

Denominator: N²QOD QCDR patients, See Appendix 1

Numerator: Number of patients aged 18 years and older who had an SSI within 30 days of the index spine procedure.

\section{Rationale}

Surgical-site infection (SSI) following spine surgery is associated with significant morbidity and economic burden that can require extended hospital stays, long-term intravenous antibiotic therapy, increased pain requirements, and delayed return to activity and work. ${ }^{67}$ Care processes that influence the incidence of spinal SSI span the first 3 major phases of care. In the preoperative phase, certain high-risk modifiable risk factors, such as diabetes, smoking, steroid and opioid use, and obesity, should be identified and corrected. ${ }^{55,80}$ Additionally, identification of active preexisting infections and routine patient decontamination are key elements. In the intraoperative phase, impeccable surgical aseptic technique, the timing and selection of antibiotic prophylaxis, and minimizing blood transfusions are key processes ${ }^{60,65,66,89,102,144}$ In the postoperative phase, aseptic wound care and early detection of wound inflammation or breakdown contribute to prevention of delayed contamination and subsequent infection.

The 30-day surveillance window was chosen based on common patient presentations for spinal SSI. The most common spinal infectious microorganisms are Staphylococcus species resulting in non-indolent infections that present with wound swelling, tenderness, erythema, drainage, or dehiscence within this time frame. ${ }^{1,24}$ Furthermore, all patients in the registry receive active follow-up at the 3-month time frame, including assessment for SSI, with documented data completeness of $98.1 \%$ with follow-up of $85 \%$ of patients at that time point. ${ }^{9}$ In summary, tracking rates of SSI in spinal surgery is essential to help determine causes of and to reduce the incidence of spine-related SSI. 


\section{N2QOD Spine Care Measure 7: Complication Following Spine-Related Procedure}

\author{
NQS Domain: Effective Clinical Care \\ PQRS No./NQF No.: Non-PQRS; modification of NQF \\ 0705
}

\section{Measure Type (Process/Outcome): Outcome}

Description: Proportion of patients undergoing spinerelated procedures who have a complication (specifically, deep venous thrombosis [DVT], pulmonary embolism [PE], myocardial infarction [MI], stroke, urinary tract infection [UTI], or unexpected new neurological deficit) in the 30-day postprocedure period.

Denominator: N²QOD QCDR patients, See Appendix 1

Numerator: Number of patients undergoing spine-related procedures who have a complication (specifically, DVT, PE, MI, stroke, UTI, or unexpected new neurological deficit) in the 30-day postprocedure period.

\section{Rationale}

Although overall complication rates for elective spine surgery are low, certain potentially preventable complications of spine surgery, namely DVT, PE, MI, stroke, UTI, and unexpected neurological deficit, are associated with significant morbidity and economic burden resulting in functional impairment, increased resource utilization, and delayed return to activity and work. ${ }^{3,9,13,34,81}$ A recent analysis of the $\mathrm{N}^{2} \mathrm{QOD}$ Spine Registry found a $2.2 \%$ incidence of major adverse events within the first 30 days after elective spine surgery. ${ }^{9}$ The prevalence of spine-related procedures (perhaps over 300,000 patients per year) translates into a significant opportunity to improve care and increase national health care value by tracking postsurgical complications.

Care processes that influence the incidence of these complications span the first 3 major phases of care. In the preoperative phase, certain high-risk modifiable risk factors, mainly insulin-dependent diabetes, smoking, and long-term steroid use, should be identified and mitigated. ${ }^{80,83,125,127,141,143,159}$ In the intraoperative phase, attention to physiological parameters, use of neuromonitoring adjuncts, judicious use of autologous blood transfusions, and shorter surgical times all reduce the likelihood of complications. ${ }^{60,155}$ In the postoperative phase, appropriate mechanical and chemical prophylaxis for venous thrombosis, timely removal of urinary catheters, meticulous blood glucose control, appropriate mobilization of patients, and close neurological monitoring can reduce the incidence of these events. ${ }^{31,79,98}$ Implementation of most of these factors is nonuniform and often varies by physician within a given institution, leading to variability in complication rates and types.

\section{$N^{2}$ QOD Spine Care Measure 8: Hospital Mortality Following Spine Procedure}

NQS Domain: Effective Clinical Care

PQRS No./NQF No.: Non-PQRS; modification of PQRS 345, modification of NQF 0119

$$
\text { Measure Type (Process/Outcome): Outcome }
$$

Description: Percentage of patients aged 18 years and older undergoing index spine procedure who die, including all deaths occurring during the hospitalization in which the spine procedure was performed, even if after 30 days.

Denominator: N²QOD QCDR patients, See Appendix 1

Numerator: Number of patients aged 18 years and older undergoing index spine procedure who die, including all deaths occurring during the hospitalization in which the spine procedure was performed, even if after 30 days.

\section{Rationale}

Mortality is the most important negative outcome associated with any surgical procedure. Mortality after elective spine surgery is rare, as demonstrated by a recent analysis of the $\mathrm{N}^{2} \mathrm{QOD}$ Spine Registry, which found a $0.3 \%$ overall perioperative mortality rate following elective spine surgery. ${ }^{9}$ Mortality is impacted by processes that span the first 3 major phases of care. In the preoperative phase, certain high-risk modifiable risk factors, longterm opioid use, smoking, uncontrolled diabetes, should be identified and mitigated. ${ }^{51,60,83,88,129}$ In the intraoperative phase, careful hemostasis and reduced blood loss, judicious use of autologous blood transfusions, and shorter surgical times all reduce the likelihood of mortality. ${ }^{60,131,141}$ In the postoperative phase, appropriate mechanical and chemical prophylaxis for venous thrombosis, appropriate mobilization of patients, close neurological monitoring, and timely resumption of cardiac and cerebrovascular prophylactic medications (antithrombotic and anticoagulants) can also reduce mortality. ${ }^{131}$ Intraoperative or postoperative cerebrovascular accidents (CVAs) or MIs dramatically increase perioperative mortality rates and surgical risk. Further perioperative surveillance measures to reduce CVAs directly impact mortality ${ }^{81}$ Implementation of most of these factors is nonuniform and often varies by physician within a given institution, leading to variability in complication rates and types.

In summary, although overall mortality rates for elective spine surgery are low, the prevalence of these procedures (perhaps over 300,000 patients per year) translates into a significant opportunity to improve care and increase national health care value by tracking immediate postsurgical deaths.

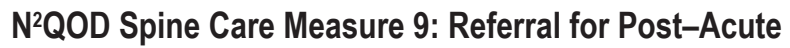 Care Rehabilitation Following Spine Procedure}

\section{NQS Domain: Effective Clinical Care}

PQRS No./NQF No.: Non-PQRS; modification of PQRS 36

\section{Measure Type (Process/Outcome): Process}

Description: Percentage of patients undergoing spine procedure who are prescribed physical therapy in the 3-month period following the index procedure.

Denominator: $\mathrm{N}^{2} \mathrm{QOD}$ QCDR patients, See Appendix 1

Numerator: Number of patients undergoing spine procedure who are prescribed physical therapy in the 3-month period following the index procedure. 


\section{Rationale}

Post-acute care inpatient rehabilitation can be an important adjunct to surgical therapies for spinal disorders. Use of rehabilitation services after spine-related surgeries have been shown to improve both back and leg pain and improve overall back-related functional status compared with results for patients who receive no rehabilitation. ${ }^{43,87,100}$ Physical therapy, including gait training, has also been shown to improve mobility and reduce the incidence of complications such as DVT and PE. ${ }^{143}$ The time frame during which these rehabilitation programs have shown to have proven efficacy span the period from immediately postoperatively with inpatient rehabilitation services to programs starting 4 to 6 weeks postsurgery. Accurate assessment of postsurgical physical therapy assignment is essential to assess the impact of these interventions, better understand overall resource utilization in spine care, and assist in the planning of continuing care.

\section{N2QOD Spine Care Measure 10: Unplanned Reoperation Following Spine Procedure Within the 30-Day Postoperative Period}

NQS Domain: Patient Safety (also Efficiency and Cost Reduction)

PQRS No./NQF No.: Non-PQRS; modification of PQRS 355

\section{Measure Type (Process/Outcome): Outcome}

Description: Percentage of patients aged 18 years and older who had any unplanned reoperation for a spine-related procedure within the 30-day postoperative period.

Denominator: $\mathrm{N}^{2} \mathrm{QOD}$ QCDR patients, See Appendix 1

Numerator: Number of patients aged 18 years and older who had any unplanned reoperation for a spine-related procedure within the 30 -day postoperative period.

\section{Rationale}

Unplanned reoperations after spine surgery delay recovery and can impact the functional outcomes of our patients, while contributing to rising health care costs. It is thus important to measure and report their rate after spinal procedures. Reoperations are among the most common complications of spine surgery. Several studies have used our proposed measure to quantify this phenomenon.

A recent analysis of the $\mathrm{N}^{2}$ QOD Spine Registry for 4970 patients who underwent lumbar spine surgery from 2012 to 2014 revealed an overall 90-day reoperation rate of 2.3\% ${ }^{86}$ In addition, a study of the American College of Surgeons National Surgical Quality Improvement Program (ACS NSQIP) registry (2006-2011) revealed an overall 30-day reoperation rate of $3.2 \%$ for spine surgery patients. ${ }^{13}$ In a different study of the same population, reoperation was the second most common unexpected postoperative outcome and accounted for almost one-third of all adverse events. In addition, spine pathologies are diverse, and reoperation rates vary by procedure, and comorbidity. Analysis of single level lumbar discectomy data (2010-2012) from the SPORT trial (242 patients) demonstrated a 1-year reoperation rate of $7 \% .{ }^{116}$ Patients who underwent the same procedure and were registered in ACS NSQIP experienced 30-day reoperation rates of $2 \% .^{48}$

There is an increasing body of literature on the association of reoperations with worse patient functional outcomes. Retrospective review of a prospective multicenter thoracolumbar spinal deformity database (2010-2012) revealed that reoperation within 30 days was associated with higher mean leg pain score $(3.8 \pm 3.2$ vs $3.3 \pm 2.9$, p $=0.0026$ ), higher Oswestry Disability Index (ODI) score $(34.2 \pm 21.2$ vs $25.7 \pm 19.2, p=0.04)$, and lower SRS-22 scores $(3.2 \pm 1$ vs $3.6 \pm 1.1, \mathrm{p}=0.04) .{ }^{123}$ In addition, a retrospective study of 149 patients undergoing surgery for spinal deformity found that reoperation in the first 2 years following surgery was associated with significantly reduced scores on measures of health-related quality of life. ${ }^{121}$

In summary, reoperations are common in spine surgery, and the existing literature extensively references use of readmission metrics similar to our proposed measure. The prevalence of unplanned reoperations and their impact on functional outcomes and quality of life make them a clear target for quality improvement.

\section{N²OD Spine Care Measure 11: Unplanned Readmission Following Spine Procedure Within the 30-Day Postoperative Period}

NQS Domain: Patient Safety (also Efficiency and Cost Reduction)

PQRS No./NQF No.: Non-PQRS; modification of PQRS 356

\section{Measure Type (Process/Outcome): Outcome}

Description: Percentage of patients aged 18 years and older who had any unplanned readmission for spine-related procedure within the 30-day postoperative period.

Denominator: N²QOD QCDR Patients, See Appendix 1

Numerator: Number of patients aged 18 years and older who had any unplanned readmission for spine-related procedure within the 30-day postoperative period.

\section{Rationale}

Unplanned postoperative readmissions contribute significantly to excessive resource utilization and drive increased health care cost. Consequently, readmissions have been under increasing scrutiny by CMS. Their prevalence is high in spine surgery, and we believe our proposed metric captures their magnitude, in accordance with national standards.

Analysis of 343,068 Medicare patients in the period 2003-2007 revealed an overall 30-day readmission rate of $7.3 \%$ for lumbar operations. The most common cause of readmission in this cohort was surgical complications, which accounted for $26 \%-33 \%$ of all events. ${ }^{149}$ Analysis of the 2011 and 2012 ACS NSQIP data revealed an overall unplanned readmission rate of $4.4 \%$. The most common etiology was wound complications (38.6\%), including superficial and deep infection, hematoma, or seroma development. ${ }^{113}$ In neurosurgery-specific data, a study of 4970 patients undergoing lumbar spine surgery in the $\mathrm{N}^{2} \mathrm{QOD}$ registry demonstrated an overall 30 -day readmission rate of $3.7 \%$, with a 90 -day readmission rate of $8.9 \% .^{9}$ Read- 
missions varied by pathology and operation, with $2.4 \%$ of patients with disc herniation, $3.4 \%$ of patients with spondylolisthesis, and $4.9 \%$ of patients with spinal stenosis requiring readmission within 30 days. ${ }^{9}$ This reflects the fact that spine surgery encompasses a variety of different pathologies and procedures, and rates of readmission vary between these different entities. Subgroup analysis of 2011 ACS NSQIP data also revealed differences in unplanned readmission rates between diagnoses, with 3.5\% of patients with disc herniation being readmitted within 30 days as compared with $6.4 \%$ of patients with acquired spondylolisthesis. ${ }^{69}$ A study of 197 patients with primary and 164 patients with metastatic tumors of the spine revealed unplanned readmission rates of $6.1 \%$ and $16.8 \%$, respectively. ${ }^{120}$

Readmissions are often associated with poor outcomes and increased hospitalization costs. Analysis of 185,954 Medicare patients undergoing spine surgery from 20052007 revealed that readmissions account for a substantial proportion $(20 \%-50 \%)$ of variation in cost between hospitals, even after accounting for spinal fusions. ${ }^{124}$

In summary, readmissions clearly represent a large driver of cost in some settings and are often the result of wound-site complications. Thus, readmission rates are important to measure for surgical quality improvement efforts by providers, payers, and administrators.

\section{$N^{2}$ QOD Spine Care Measure 12: Selection of Prophylactic Antibiotic Prior to Spine Procedure}

\section{NQS Domain: Patient Safety}

PQRS No./NQF No.: Non-PQRS; modification of PQRS 21, NQF 0268

\section{Measure Type (Process/Outcome): Process}

Description: Percentage of patients aged 18 years and older undergoing an index spine-related procedure with the indications for prophylactic antibiotics who had an order for antimicrobial prophylaxis.

\section{Denominator: $\mathrm{N}^{2} \mathrm{QOD}$ QCDR Patients, See Appendix 1}

Numerator: Number of patients aged 18 years and older undergoing an index spine-related procedure with the indications for prophylactic antibiotics who had an order for antimicrobial prophylaxis.

\section{Rationale}

Surgical-site infection is a potentially preventable cause of increased morbidity and mortality for spine patients. From a policy perspective, these complications contribute to mounting health care costs. Wound infection was found to be the most common precipitating event (38.6\%) of 30day readmissions in the 2012 ACS NSQIP data for 15,668 patients undergoing lumbar spine surgery. ${ }^{113}$ The National Healthcare Safety Network (2006-2007) demonstrated an SSI rate of $2.8 \%-9.7 \%$ for spine surgery.$^{37}$ Given the magnitude and the potential impact of postoperative infections on spine patients, establishing process measures to, in part, prevent these complications is of paramount importance.

Preoperative prophylactic antibiotics are central in preventing postoperative infections, and their use is an ideal quality improvement target. A meta-analysis of 6 random- ized trials evaluating prophylactic antibiotic efficacy in spine surgery demonstrated that their use resulted in significantly reduced postoperative infection rates (OR 0.37 , $95 \%$ CI $0.17-0.78, p<0.01$ ). The majority of these trials used a cephalosporin (such as cefazolin) or $\beta$-lactam antibiotic (such as oxacillin), though one trial used vancomycin and gentamicin. ${ }^{10}$ The most common pathogens causing postoperative infections in spinal surgery are Staphylococcus aureus, coagulase-negative staphylococci, $\beta$-hemolytic streptococci, and gram-negative bacilli. Cefazolin is the current agent of choice for prophylaxis in spine surgery, given its activity against Staphylococcus species and $\beta$-hemolytic Streptococcus. ${ }^{18}$ Vancomycin and clindamycin are common choices in patients who have adverse reactions or allergies to cephalosporins and $\beta$-lactam antibiotics.

However, resistance is increasingly a problem for firstand second-generation cephalosporins and $\beta$-lactam antibiotics. A study of 7529 patients undergoing any spine surgery was reported to the CDC NHSN database. ${ }^{1}$ In this sample the most common pathogen of postoperative spine infections was S. aureus (45.2\%), followed by Staphylococcus epidermidis (31.4\%). Methicillin-resistant organisms were present in $34.3 \%$ of cases, and gram-negative organisms (61.6\% cefazolin resistant) were found in $30.5 \%$ of cases. This could reflect selection bias, since reported infections may predominantly represent resistant organisms in an institution that routinely uses preoperative antibiotics. Appropriate prophylactic antibiotics should be tailored to institutional patterns of antimicrobial resistance.

In summary, given the current evidence for efficacy of antibiotic prophylaxis in the prevention of postoperative infections in spine surgery, ensuring their use would likely improve surgical outcomes. Routine antibiotic prophylaxis in this patient population therefore constitutes an important quality-improvement metric. For most procedures, cefazolin is the drug of choice for prophylaxis due to its proven efficacy. It has a desirable duration of action and spectrum of activity against organisms commonly encountered in surgery, reasonable safety, and low cost. However, vancomycin or clindamycin may be effectively used in patients with serious allergy or adverse reactions to $\beta$-lactams.

\section{N2QOD Spine Care Measure 13: Discontinuation of Prophylactic Parenteral Antibiotics Following Spine Procedure}

NQS Domain: Patient Safety

PQRS No./NQF No.: Non-PQRS; modification of PQRS 22, PQRS 45, NQF 0271

\section{Measure Type (Process/Outcome): Process}

Description: Percentage of patients aged 18 years and older undergoing index spine procedures with the indications for prophylactic parenteral antibiotics and who received a prophylactic parenteral antibiotic, who have an order for discontinuation of prophylactic parenteral antibiotics within 24 hours of procedure end time.

Denominator: $\mathrm{N}^{2} \mathrm{QOD}$ patients who received prophylactic antibiotics, QCDR patients, See Appendix 1

Numerator: Number of patients aged 18 years and older undergoing index spine procedures with the indications 
for prophylactic parenteral antibiotics and who received a prophylactic parenteral antibiotic, who have an order for discontinuation of prophylactic parenteral antibiotics within 24 hours of procedure end time.

\section{Rationale}

Although appropriate use of prophylactic antibiotics can prevent long-term complications after spine surgery and decrease cost, excessive utilization can contribute to the development of pan-resistant microbes, with potential catastrophic impact on health care outcomes and cost.

Published data question the efficacy of prophylactic antibiotic administration extending past the first 24 hours postoperatively. A meta-analysis of 28 randomized trials comparing single- and multiple-dose regimens failed to demonstrate any advantage for the latter. ${ }^{85}$ From 1597 patients undergoing lumbar spine surgery between 1999 and 2004, $0.8 \%$ developed a postoperative infection after receiving multiple doses of prophylactic antibiotics, whereas $0.4 \%$ had a similar complication after a single dose. This difference was not significant. However, culture results demonstrated increased prevalence of resistant organisms $(83 \%)$ in the multiple-dose group compared with the singledose group $(0 \%){ }^{64}$ Similarly, another study of 284 patients undergoing lumbar spine surgery without instrumentation compared prolonged and limited prophylactic antibiotic regimens and did not identify a difference in the rate of postoperative infections $(2.8 \%$ in the prolonged regimen vs $1.4 \%$ in the limited group). Two of the patients in the multiple-dose group went on to develop Clostridium difficile colitis. ${ }^{62}$

Prolonged antibiotic use has also shown no benefit in other surgical subspecialties and is associated with increased risk of secondary infections. In a retrospective review of 201 cases of $C$. difficile colitis, 55\% of the cases were related to prolonged perioperative antibiotic prophylaxis. ${ }^{61}$ A study of 114 postoperative ICU patients found that bacteremia (17\% vs $3 \%$ ) and line infections (15\% vs $2 \%$ ) were more common in patients receiving more than 4 days of prophylactic antibiotics compared with those receiving 1 day of antibiotics. Additionally the authors noted an excess hospitalization cost of $\$ 40,000$ for patients with prolonged regimens, during the study period..$^{95}$ Lastly, continued antibiotic use increases the risk of allergic reactions, and drug interactions. ${ }^{19}$

In summary, the shortest effective duration of antimicrobial administration to prevent postoperative infection is not known. However, evidence is mounting that prolonged postoperative antimicrobial administration is not necessary for most spinal procedures. Prophylactic antibiotics should be discontinued within 24 hours after the operation to prevent patient-level complications, contain health care costs, and protect the community from the development of resistant bacterial strains. Therefore, tracking the appropriate discontinuation of prophylactic antibiotics is a crucial quality measure for spine surgery.

\section{N2$^{2}$ QOD Spine Care Measure 14: Medicine Reconciliation Following Spine-Related Procedure}

NQS Domain: Communication and Care Coordination
PQRS No./NQF No.: Non-PQRS; modification of PQRS 46

\section{Measure Type (Process/Outcome): Process}

Description: Percentage of patients aged 18 years and older undergoing spine-related procedures, discharged from operative facility, and seen within 30 days following discharge in the office by the physician, prescribing practitioner, registered nurse, who had a reconciliation of the discharge medications with the current medication list documented in the outpatient medical record.

Denominator: $\mathrm{N}^{2} \mathrm{QOD}$ QCDR patients, See Appendix 1

Numerator: Number of patients aged 18 years and older undergoing spine-related procedures, discharged from operative facility, and seen within 30 days following discharge in the office by the physician, prescribing practitioner, registered nurse, who had a reconciliation of the discharge medications with the current medication list documented in the outpatient medical record.

\section{Rationale}

Incomplete or inaccurate medication reconciliation is widespread ${ }^{45,142}$ and has been associated with adverse events, including drug interactions, ${ }^{154}$ dangerous starting or cessation of medications for chronic conditions, ${ }^{14,59,139}$ and avoidable hospital readmission. ${ }^{68}$ Hospitalization puts patients at high risk for medication errors after discharge at least in part because medication records are often incomplete. $^{14,75}$ Medication reconciliation postdischarge is, therefore, a critical component of care coordination. Postdischarge medication reconciliation is an important opportunity to catch potentially harmful omissions or changes in prescribed medications, particularly in elderly patients who are prescribed a greater quantity and variety of medications. ${ }^{77}$ Although the magnitude of the effect of medication reconciliation alone on patient outcomes is not well studied, there is agreement among experts that potential benefits outweigh the harm..$^{30,59,72,112}$ Postdischarge medication reconciliation is an effective tool to reduce preventable adverse drug events associated with injury or death $^{57,112}$ and minimize duplication and complexity of a medication regimen to support adherence, ${ }^{153}$ and it has the potential to reduce emergency department visits ${ }^{71}$ hospital readmission rates, ${ }^{68,71}$ and morbidity. ${ }^{42}$ Postdischarge medication reconciliation is recommended by the Joint Commission patient safety goals ${ }^{50}$ the American Geriatric Society,$^{30}$ and the Society of Hospital Medicine, ${ }^{73}$ and measurement of postdischarge medication reconciliation is a priority area of the National Quality Forum and the National Priorities Partnership. ${ }^{96}$

\section{N²QD Spine Care Measure 15: Risk Assessment for Elective Spine Procedure}

NQS Domain: Communication and Care Coordination

PQRS No./NQF No.: Non-PQRS; PQRS 182, modification of PQRS 358

\section{Measure Type (Process/Outcome): Process}

Description: Percentage of patients who underwent elective therapy(-ies) for spine-related disorders with documentation of risk factor assessment by their treatment team 
prior to therapy and who received personal discussion of those documented risks with the health care provider.

\section{Denominator: N²QOD QCDR patients, See Appendix 1}

Numerator: Number of patients who underwent elective therapy(-ies) for spine-related disorders with documentation of risk factor assessment by their treatment team prior to therapy and who received personal discussion of those documented risks with the health care provider.

\section{Rationale}

Preoperative risk assessment and communication between surgeons and patients is critical for effective informed consent and shared decision making in surgical care. Shared decision making is considered an integral component of patient-centered care, especially for preference-sensitive issues. ${ }^{11,58}$ Evidence suggests that there is room for improving the informed consent and shared decision-making process..$^{5,17,130}$ Use of a risk calculator helps improve the quality of the informed consent and shared decision-making process by providing a personalized, customized, and empirically based estimate of a patient's risk of postoperative complications. Moreover, evidence suggests that sharing numeric estimates of patient-specific risk may enhance patients' trust in providers.

The ACS NSQIP now offers a risk calculator that can be used for operations in many surgical subspecialties including spine surgery. ${ }^{16}$ ACS NSQIP data have been used to identify a number of predictors of postoperative complications and mortality following spine surgery. ${ }^{126}$ The international spine study group demonstrated the feasibility of using a multicenter prospective database to identify predictors of surgical complications and health-related quality of life following spinal deformity surgery. ${ }^{76,128,136,137}$ Others have also developed models for predicting postoperative medical complications. ${ }^{78}$ A recent analysis of the $\mathrm{N}^{2} \mathrm{QOD}$ Spine Registry found that certain covariates were strongly associated with patient outcomes following elective spine surgery. Among the most important variables were patient educational status, occupation, diagnosis, baseline patientreported outcomes, and smoking status..$^{104}$

\section{$\mathrm{N}^{2}$ QOD Spine Care Measure 16: Depression and Anxiety Assessment Prior to Spine-Related Therapies}

NQS Domain: Communication and Care Coordination PQRS No./NQF No.: Non-PQRS

Measure Type (Process/Outcome): Process

Description: Percentage of patients aged 18 years and older with documentation of depression and/or anxiety assessment through discussion with the patient including the use of a standardized assessment tool prior to index therapy(-ies) for treatment of spine-related pain symptoms.

\section{Denominator: $\mathrm{N}^{2} \mathrm{QOD}$ QCDR patients, See Appendix 1}

Numerator: Number of patients aged 18 years and older with documentation of depression and/or anxiety assessment through discussion with the patient including the use of a standardized assessment tool prior to index therapy(ies) for treatment of spine-related pain symptoms.

\section{Rationale}

Preoperative psychological screening is emerging as an important method to predict outcomes following elective spine surgery and potentially identify modifiable conditions to improve spine care outcomes. Depression and anxiety are prevalent in patients undergoing spine surgery. A recent analysis of the $\mathrm{N}^{2} \mathrm{QOD}$ Spine Registry found that $12.8 \%$ and $21.3 \%$ of patients undergoing elective spine surgery identified themselves as anxious or depressed, respectively. Furthermore, baseline depression and anxiety were strongly associated with patient outcomes following elective spine surgery. There is evidence that depression and anxiety predict outcomes, including return to work, ${ }^{105}$ medical complications, ${ }^{78}$ functional recovery, ${ }^{29,133}$ and quality of life..$^{0}$ Screening may aid in appropriate patient selection. In one large prospective study, depressive symptoms predicted functional improvement after nonsurgical treatment of chronic low-back pain. ${ }^{53}$ Screening may also guide interventions aimed at treating depression and anxiety that can in turn improve outcomes after spine surgery. In one study, patients whose depression improved after spine surgery had improved outcomes resembling those of nondepressed patients. ${ }^{134}$ Despite the evidence for screening, only a minority of spine surgeons currently screen for psychological factors, ${ }^{160}$ suggesting that there is an opportunity to improve outcomes by encouraging screening.

\section{N²OD Spine Care Measure 17: Narcotic Pain Medicine Management Following Elective Spine Procedure}

NQS Domain: Communication and Care Coordination PQRS No./NQF No.: Non-PQRS; modification of PQRS 180

\section{Measure Type (Process/Outcome): Process}

Description: Percentage of patients aged 18 years and older who underwent elective therapies for spine-related pain who were assessed for narcotic use/requirements at the time of discharge.

The performance measure was met if the patient 1) was not receiving narcotics postdischarge or 2) was receiving narcotics for pain for less than 2 weeks postdischarge or 3) was expected to require narcotics for more than 2 weeks after the index procedure and a narcotic use management plan was documented.

Denominator: N²QOD QCDR Patients, See Appendix 1

Numerator: Number of patients aged 18 years and older who underwent elective therapies for spine-related pain who were assessed for narcotic use/requirements at the time of discharge.

The performance measure was met if the patient 1) was not receiving narcotics post-discharge or 2) was receiving narcotics for pain less than 2 weeks postdischarge or 3 ) was expected to require narcotics for more than 2 weeks after the index procedure and a narcotic use management plan was documented.

\section{Rationale}

Narcotic medications are an important part of postoperative pain management in patients undergoing spinal 
surgery. However, long-term use of narcotics should be avoided due to adverse effects, the risk of opioid dependence, and diminished effectiveness in treating pain..$^{25,27}$ Chronic opioid therapy places patients at risk for intolerable adverse effects, aberrant drug-related behaviors, opioid dependence, and failure to make progress toward therapeutic goals. Furthermore, total pain relief with chronic opioid therapy is rare. Trials suggest that improvement averages less than 2 to 3 points on a $0-10$ scale. ${ }^{41,63}$ Monitoring length and dose of narcotic pain medication for patients undergoing spinal procedures is integral to appropriate management. Preoperative opioid use is strongly associated with persistent opioid use after surgery, making it feasible to predict which patients will require longerterm narcotic management. ${ }^{6,76}$ In cases of chronic opioid therapy, it is important for clinicians to discuss a management plan prior to initiating a course of treatment and on an ongoing basis while patients are on therapy, with plans varying based on patient needs and risks. ${ }^{27,40}$

\section{N2QOD Spine Care Measure 18: Smoking Assessment and Cessation Coincident With Spine-Related Therapies}

NQS Domain: Community and Population Health

PQRS No./NQF No.: Non-PQRS; modification of PQRS 226, modification of NQF 0028

\section{Measure Type (Process/Outcome): Process}

Description: Percentage of patients aged 18 years and older who were assessed for tobacco use prior to spinerelated therapy(-ies) and who received cessation counseling intervention if identified as a tobacco user.

Denominator: N²QD QCDR patients, See Appendix 1

Numerator: Number of patients aged 18 years and older who were assessed for tobacco use prior to spinerelated therapy(s) and who received cessation counseling intervention if identified as a tobacco user.

\section{Rationale}

There is a growing body of evidence regarding the negative impact of cigarette smoking on outcomes following spine surgery. Smoking, nicotine exposure, and tissue hypoxemia have been identified to have deleterious effects on wound healing, general spine and bone health, and bony fusion. 52,56,97,110,111,132 Clinically, smoking has been shown to increase the risk of pseudarthrosis (nonunion), SSI, reoperation, and overall patient dissatisfaction. . $^{420,22,23,118,156}$ These negative effects have been observed not only for fusion operations, but also simple laminectomy, and across all age groups.

Interventions targeting smoking cessation have been shown to decrease these complications as well as those associated with general perioperative risk from non-spine surgery. ${ }^{44,91}$ Furthermore, cessation of smoking has been shown to decrease spine pain even in medically managed patients. $^{12}$

A recent analysis of the $\mathrm{N}^{2} \mathrm{QOD}$ database revealed that $17 \%$ of patients undergoing elective spine surgery identified themselves as active smokers. An analysis of the same database identified smoking as a significant driver of postsurgery outcomes. ${ }^{104}$ Smoking assessments and cessation interventions hold the potential to significantly improve outcomes following elective spine surgery.

\section{N2QOD Spine Care Measure 19: Body Mass Assessment and Follow-Up Coincident With Spine-Related Therapies}

NQS Domain: Community and Population Health

PQRS No./NQF No.: Non-PQRS; modification of PQRS 128, modification of NQF 0421

\section{Measure Type (Process/Outcome): Process}

Description: Percentage of patients aged 18 years and older with a weight and height recorded at the time of initial evaluation and/or treatment of spine-related disorder documented in the medical record and a documented follow-up plan (baseline), if the most recent body mass index (BMI), calculated as $\mathrm{kg} / \mathrm{m}^{2}$, is outside of normal parameters (BMI $\geq 23$ and $<30$ for patients 65 years and older; $\mathrm{BMI} \geq 18.5$ and $<25$ for patients $18-64$ years of age).

If the most recent documented BMI is outside of normal parameters, then a follow-up plan must be documented during the encounter or during the 6 months immediately preceding the current encounter. The documented follow-up plan must be based on the most recent documented BMI outside of normal parameters (example: "Patient referred to nutrition counseling for BMI above normal parameters"). If more than $1 \mathrm{BMI}$ is reported during the measure period, the most recent BMI will be used to determine if the performance has been met.

Denominator: $\mathrm{N}^{2} \mathrm{QOD}$ QCDR patients. See Appendix 1

Numerator: Number of patients aged 18 years and older with a weight and height recorded at time of initial evaluation and/or treatment of spine-related disorder documented in the medical record and documentation of a follow-up plan (baseline) if the most recent BMI is outside of normal parameters.

\section{Rationale}

Obesity, defined as a BMI greater than or equal to $30 \mathrm{~kg} / \mathrm{m}^{2}$, has a prevalence of approximately $34 \%$ in the United States. ${ }^{99}$ It has long been recognized that obese patients are at increased risk for complications related to nearly all types of surgery. ${ }^{109}$ Patients suffering from obesity may be more likely to present to a spine surgeon for potential treatment, as obesity is a significant risk factor for spine disease. ${ }^{114}$ Spinal surgery in the obese population has also been found to be associated with higher risk for many adverse outcomes. ${ }^{21,38,82,84,119}$ These outcomes include higher volumes of blood loss during surgery, greater length of hospital stay, and higher incidence of inadvertent durotomy, as well as higher rates of reoperation. Outside of immediate perioperative complications, obese patients have been found to have a higher rate of persistent and new symptoms (specifically, radiculopathy and spinal neurological deficits) following surgery as compared with a non-obese population. ${ }^{115}$

In summary, obesity has also been shown to influence incidence of spinal disorders and also outcomes after spinal procedures. Effective co-management of obesity is integral to appropriate treatment of most spinal conditions. 


\section{N²OD Spine Care Measure 20: Unhealthy Alcohol Use Assessment Coincident With Spine Care}

NQS Domain: Community and Population Health

PQRS No./NQF No.: Non-PQRS; modification of PQRS 173

\section{Measure Type (Process/Outcome): Process}

Description: Percentage of patients aged 18 years and older being treated for spine-related disorders who were assessed for unhealthy alcohol use prior to index therapy(ies) for treatment of spine-related pain symptoms.

\section{Denominator: $\mathrm{N}^{2} \mathrm{QOD}$ QCDR patients. See Appendix 1}

Numerator: Number of patients aged 18 years and older being treated for spine-related disorders who were assessed for unhealthy alcohol use prior to index therapy(ies) for treatment of spine-related pain symptoms.

\section{Rationale}

Alcohol consumption is ubiquitous in the United States, and variability in the quantity of consumption is significant. The lifetime prevalence of any type of alcohol use disorder is in the range of $8 \%-18 \% .{ }^{54}$ Alcohol abuse has been associated with increased rates of postoperative complications across most major surgical procedures. These complications include postoperative wound complications (including bleeding and infections) and various cardiopulmonary complications. ${ }^{32,94,101,145-147}$ Preoperative intervention for patients consuming excessive alcohol on a daily basis and abstinence before surgery has been shown to abate some of these risks. ${ }^{101,145}$

Although few analyses point to a direct association between outcomes of spine care and alcohol consumption, a negative correlation between chronic heavy alcohol consumption and bone mineral density (including that of the spine) has been identified..$^{70}$ This evidence indirectly supports the benefit of screening for alcohol use prior to prescribing spine surgery.

Screening for unhealthy alcohol use can identify patients whose habits may put them at risk for adverse health outcomes due to their alcohol use. While this measure does not require counseling for those patients to be found at risk, brief counseling interventions have shown to be effective in reducing alcohol use. It would be expected that if a provider found his or her patient to be at risk after screening that intervention would be provided.

A systematic method of assessing for unhealthy alcohol use should be used. Please refer to the National Institute on Alcohol Abuse and Alcoholism publication Helping Patients Who Drink Too Much: A Clinician's Guide for additional information regarding systematic screening methods. ${ }^{95}$

\section{$\mathrm{N}^{2}$ QOD Spine Care Measure 21: Participation in a Systematic National Database for Spine Care Interventions}

NQS Domain: Community and Population Health 0456

PQRS No./NQF No.: Non-PQRS; modification of NQF

Measure Type (Process/Outcome): Process

Description: Participation in a multicenter spine care data collection and feedback program that provides benchmarking of the physician's data relative to national programs and uses structural, process, and outcome measures.

Denominator: Participant in the QCDR with submission of 1 or more cases

Numerator: Participation in the $\mathrm{N}^{2} \mathrm{QOD}$ QCDR with submission of 20 or more cases in at least 1 multicenter spine-care data collection and feedback program that provides benchmarking of the physician's data relative to national programs and uses structural, process, and outcome measures $($ Met $=1$, Else $=0)$.

\section{Rationale}

Participation in a clinical database registry allows physicians to monitor clinical performance, detect infrequent complications, and build the robust clinical research infrastructure necessary to advance the science surrounding quality in managing spinal conditions. ${ }^{7,8,86,140}$ In this latter capacity, this registry will serve as a tool for conducting research in areas of comparative effectiveness, cost effectiveness, and appropriate use criteria. In addition, participation science has shown that use of structured measurement allows practitioners to compare their performance against risk-adjusted benchmarks to improve individual and site health care quality. There exist numerous other national and local registries in surgery as well as various surgical specialties including thoracic, trauma, transplant, oncology, etc. ${ }^{15,140}$ Interestingly, a systematic review has identified that several of these programs have identified decreases in risk-adjusted mortality associated with registry participation..$^{140}$

\section{Conclusions}

Regulatory pressures have created a complex network of quality requirements to be met by physicians and practices. The common denominator of all these initiatives is that to avoid penalties, physicians must meet existing "generic" standards quality standards, which in the case of neurosurgery and many other medical specialties, are not pertinent to everyday clinical practice. Recent developments in national quality reporting programs, such as QCDR, have enhanced the ability of specialty groups to develop truly relevant measures of health care quality. The $\mathrm{N}^{2} \mathrm{QOD}$ became an approved QCDR in the PQRS for the 2015 program year, offering 21 non-PQRS measures, initially focused on spine procedures, which are the first specialty-specific measures for neurosurgery. Securing QCDR status for $\mathrm{N}^{2} \mathrm{QOD}$ is a tremendously important accomplishment for our specialty. This program will ensure that data collected through our registries and used for PQRS is meaningful for neurosurgeons, their patients, and other stakeholders. The $2015 \mathrm{~N}^{2} \mathrm{QOD}$ QCDR is further evidence of neurosurgery's commitment to substantively advancing the health care quality paradigm. With the added incentive of using our registry to fulfill PQRS requirements, we anticipate that the volume of collected data should grow exponentially, thereby increasing the quality improvement and research value of the registry. 


\section{Acknowledgments}

A portion of this work was supported through a grant from the Neurosurgery Research and Education Foundation (NREF).

\section{References}

1. Abdul-Jabbar A, Berven SH, Hu SS, Chou D, Mummaneni PV, Takemoto S, et al: Surgical site infections in spine surgery: identification of microbiologic and surgical characteristics in 239 cases. Spine (Phila Pa 1976) 38:E1425E1431, 2013

2. Abou-Setta AM, Beaupre LA, Rashiq S, Dryden DM, Hamm MP, Sadowski CA, et al: Comparative effectiveness of pain management interventions for hip fracture: a systematic review. Ann Intern Med 155:234-245, 2011

3. Akeda K, Matsunaga H, Imanishi T, Hasegawa M, Sakakibara T, Kasai Y, et al: Prevalence and countermeasures for venous thromboembolic diseases associated with spinal surgery: a follow-up study of an institutional protocol in 209 patients. Spine (Phila Pa 1976) 39:791-797, 2014

4. Andersen T, Christensen FB, Laursen M, Høy K, Hansen ES, Bünger C: Smoking as a predictor of negative outcome in lumbar spinal fusion. Spine (Phila Pa 1976) 26:26232628,2001

5. Ankuda CK, Block SD, Cooper Z, Correll DJ, Hepner DL, Lasic M, et al: Measuring critical deficits in shared decision making before elective surgery. Patient Educ Couns 94:328-333, 2014

6. Armaghani SJ, Lee DS, Bible JE, Archer KR, Shau DN, Kay $\mathrm{H}$, et al: Preoperative opioid use and its association with perioperative opioid demand and postoperative opioid independence in patients undergoing spine surgery. Spine (Phila Pa 1976) 39:E1524-E1530, 2014

7. Asher AL, McCormick PC, Kondziolka D: Introduction: the science of practice: addressing the challenges of modern health care. Neurosurg Focus 34(1):Introduction, 2013

8. Asher AL, McCormick PC, Selden NR, Ghogawala Z, McGirt MJ: The National Neurosurgery Quality and Outcomes Database and NeuroPoint Alliance: rationale, development, and implementation. Neurosurg Focus 34(1):E2, 2013

9. Asher AL, Speroff T, Dittus RS, Parker SL, Davies JM, Selden N, et al: The National Neurosurgery Quality and Outcomes Database (N2QOD): a collaborative North American outcomes registry to advance value-based spine care. Spine (Phila Pa 1976) 39 (22 Suppl 1):S106-S116, 2014

10. Barker FG II: Efficacy of prophylactic antibiotic therapy in spinal surgery: a meta-analysis. Neurosurgery 51:391-401, 2002

11. Barry MJ, Edgman-Levitan S: Shared decision makingpinnacle of patient-centered care. N Engl J Med 366:780781, 2012

12. Behrend C, Prasarn M, Coyne E, Horodyski M, Wright J, Rechtine GR: Smoking cessation related to improved patient-reported pain scores following spinal care. J Bone Joint Surg Am 94:2161-2166, 2012

13. Bekelis K, Desai A, Bakhoum SF, Missios S: A predictive model of complications after spine surgery: the National Surgical Quality Improvement Program (NSQIP) 20052010. Spine J 14:1247-1255, 2014

14. Bell CM, Brener SS, Gunraj N, Huo C, Bierman AS, Scales DC, et al: Association of ICU or hospital admission with unintentional discontinuation of medications for chronic diseases. JAMA 306:840-847, 2011

15. Best WR, Khuri SF, Phelan M, Hur K, Henderson WG, Demakis JG, et al: Identifying patient preoperative risk factors and postoperative adverse events in administrative databases: results from the Department of Veterans Affairs National Surgical Quality Improvement Program. J Am Coll Surg 194:257-266, 2002

16. Bilimoria KY, Liu Y, Paruch JL, Zhou L, Kmiecik TE, Ko CY, et al: Development and evaluation of the universal ACS NSQIP surgical risk calculator: a decision aid and informed consent tool for patients and surgeons. J Am Coll Surg 217:833-842, 842.e1-842.e3, 2013

17. Braddock C III, Hudak PL, Feldman JJ, Bereknyei S, Frankel RM, Levinson W: "Surgery is certainly one good option": quality and time-efficiency of informed decisionmaking in surgery. J Bone Joint Surg Am 90:1830-1838, 2008

18. Bratzler DW, Dellinger EP, Olsen KM, Perl TM, Auwaerter PG, Bolon MK, et al: Clinical practice guidelines for antimicrobial prophylaxis in surgery. Am J Health Syst Pharm 70:195-283, 2013

19. Bratzler DW, Houck PM: Antimicrobial prophylaxis for surgery: an advisory statement from the National Surgical Infection Prevention Project. Am J Surg 189:395-404, 2005

20. Brown CW, Orme TJ, Richardson HD: The rate of pseudarthrosis (surgical nonunion) in patients who are smokers and patients who are nonsmokers: a comparison study. Spine (Phila Pa 1976) 11:942-943, 1986

21. Burks CA, Werner BC, Yang S, Shimer AL: Obesity is associated with an increased rate of incidental durotomy in lumbar spine surgery. Spine (Phila Pa 1976) 40:500-504, 2015

22. Bydon M, Macki M, De la Garza-Ramos R, Sciubba DM, Wolinsky JP, Gokaslan ZL, et al: Smoking as an independent predictor of reoperation after lumbar laminectomy: a study of 500 cases. J Neurosurg Spine 22:288-293, 2015

23. Capen DA, Calderone RR, Green A: Perioperative risk factors for wound infections after lower back fusions. Orthop Clin North Am 27:83-86, 1996

24. Chahoud J, Kanafani Z, Kanj SS: Surgical site infections following spine surgery: eliminating the controversies in the diagnosis. Front Med (Lausanne) 1:7, 2014

25. Chaparro LE, Furlan AD, Deshpande A, Mailis-Gagnon A, Atlas S, Turk DC: Opioids compared with placebo or other treatments for chronic low back pain: an update of the Cochrane Review. Spine (Phila Pa 1976) 39:556-563, 2014

26. Chapman JR, Norvell DC, Hermsmeyer JT, Bransford RJ, DeVine J, McGirt MJ, et al: Evaluating common outcomes for measuring treatment success for chronic low back pain. Spine (Phila Pa 1976) 36 (21 Suppl):S54-S68, 2011

27. Chou R, Fanciullo GJ, Fine PG, Adler JA, Ballantyne JC, Davies P, et al: Clinical guidelines for the use of chronic opioid therapy in chronic noncancer pain. J Pain 10:113130, 2009

28. Chow A, Mayer EK, Darzi AW, Athanasiou T: Patientreported outcome measures: the importance of patient satisfaction in surgery. Surgery 146:435-443, 2009

29. Cobo Soriano J, Sendino Revuelta M, Fabregate Fuente M, Cimarra Díaz I, Martínez Ureña P, Deglané Meneses R: Predictors of outcome after decompressive lumbar surgery and instrumented posterolateral fusion. Eur Spine J 19:1841-1848, 2010

30. Coleman EA, Boult C: Improving the quality of transitional care for persons with complex care needs. J Am Geriatr Soc 51:556-557, 2003

31. Cox JB, Weaver KJ, Neal DW, Jacob RP, Hoh DJ: Decreased incidence of venous thromboembolism after spine surgery with early multimodal prophylaxis: Clinical article. J Neurosurg Spine 21:677-684, 2014

32. Delgado-Rodríguez M, Mariscal-Ortiz M, Gómez-Ortega A, Martínez-Gallego G, Palma-Pérez S, Sillero-Arenas M, et 
al: Alcohol consumption and the risk of nosocomial infection in general surgery. Br J Surg 90:1287-1293, 2003

33. DeVine J, Norvell DC, Ecker E, Fourney DR, Vaccaro A, Wang J, et al: Evaluating the correlation and responsiveness of patient-reported pain with function and quality-of-life outcomes after spine surgery. Spine (Phila Pa 1976) 36 (21 Suppl):S69-S74, 2011

34. Deyo RA, Hickam D, Duckart JP, Piedra M: Complications after surgery for lumbar stenosis in a veteran population. Spine (Phila Pa 1976) 38:1695-1702, 2013

35. Deyo RA, Mirza SK, Martin BI: Back pain prevalence and visit rates: estimates from U.S. national surveys, 2002. Spine (Phila Pa 1976) 31:2724-2727, 2006

36. Deyo RA, Mirza SK, Martin BI, Kreuter W, Goodman DC, Jarvik JG: Trends, major medical complications, and charges associated with surgery for lumbar spinal stenosis in older adults. JAMA 303:1259-1265, 2010

37. Edwards JR, Peterson KD, Mu Y, Banerjee S, AllenBridson K, Morrell G, et al: National Healthcare Safety Network (NHSN) report: data summary for 2006 through 2008, issued December 2009. Am J Infect Control 37:783-805, 2009

38. Elgafy H, O'Brien P, Blessinger B, Hassan A: Challenges of spine surgery in obese patients. Am J Orthop 41:E46E50, 2012

39. Fairbank J: Revised Oswestry Disability questionnaire. Spine (Phila Pa 1976) 25:2552, 2000

40. Federation of State Medical Boards of the United States, Inc: Model policy for the use of controlled substances for the treatment of pain. J Pain Palliat Care Pharmacother 19:73-78, 2005

41. Furlan AD, Sandoval JA, Mailis-Gagnon A, Tunks E: Opioids for chronic noncancer pain: a meta-analysis of effectiveness and side effects. CMAJ 174:1589-1594, 2006

42. Gillespie U, Alassaad A, Henrohn D, Garmo H, Hammarlund-Udenaes $\mathrm{M}$, Toss $\mathrm{H}$, et al: A comprehensive pharmacist intervention to reduce morbidity in patients 80 years or older: a randomized controlled trial. Arch Intern Med 169:894-900, 2009

43. Gilmore SJ, McClelland JA, Davidson M: Physiotherapeutic interventions before and after surgery for degenerative lumbar conditions: a systematic review. Physiotherapy 101:111-118, 2015

44. Glassman SD, Anagnost SC, Parker A, Burke D, Johnson JR, Dimar JR: The effect of cigarette smoking and smoking cessation on spinal fusion. Spine (Phila Pa 1976) 25:26082615,2000

45. Gleason KM, McDaniel MR, Feinglass J, Baker DW, Lindquist L, Liss D, et al: Results of the Medications at Transitions and Clinical Handoffs (MATCH) study: an analysis of medication reconciliation errors and risk factors at hospital admission. J Gen Intern Med 25:441-447, 2010

46. Gliklich R, Dreyer N, Leavy M (eds): Registries for Evaluating Patient Outcomes: A User's Guide. Washington, DC: Agency for Healthcare Research and Quality, 2014

47. Godil SS, Parker SL, Zuckerman SL, Mendenhall SK, Devin CJ, Asher AL, et al: Determining the quality and effectiveness of surgical spine care: patient satisfaction is not a valid proxy. Spine J 13: 1006-1012, 2013

48. Golinvaux NS, Bohl DD, Basques BA, Yacob A, Grauer JN: Comparison of the lumbar disc herniation patients randomized in SPORT to 6,846 discectomy patients from NSQIP: demographics, perioperative variables, and complications correlate well. Spine J 15:685-691, 2015

49. Greene J: Competition for patients spurs hospitals' concern for serving the customer. Mod Healthc 24:30-34, 1994 (Erratum in Mod Healthc 24:108, 1994)

50. Greenwald JL, Halasyamani LK, Greene J, LaCivita C,
Stucky E, Benjamin B, et al: Making inpatient medication reconciliation patient centered, clinically relevant, and implementable: a consensus statement on key principles and necessary first steps. Jt Comm J Qual Patient Saf 36:504 $513,481,2010$

51. Guzman JZ, Iatridis JC, Skovrlj B, Cutler HS, Hecht AC, Qureshi SA, et al: Outcomes and complications of diabetes mellitus on patients undergoing degenerative lumbar spine surgery. Spine (Phila Pa 1976) 39:1596-1604, 2014

52. Hadley MN, Reddy SV: Smoking and the human vertebral column: a review of the impact of cigarette use on vertebral bone metabolism and spinal fusion. Neurosurgery 41:116124, 1997

53. Hägg O, Fritzell P, Ekselius L, Nordwall A: Predictors of outcome in fusion surgery for chronic low back pain. A report from the Swedish Lumbar Spine Study. Eur Spine J 12:22-33, 2003

54. Hasin DS, Stinson FS, Ogburn E, Grant BF: Prevalence, correlates, disability, and comorbidity of DSM-IV alcohol abuse and dependence in the United States: results from the National Epidemiologic Survey on Alcohol and Related Conditions. Arch Gen Psychiatry 64:830-842, 2007

55. Hegde V, Meredith DS, Kepler CK, Huang RC: Management of postoperative spinal infections. World J Orthop 3:182-189, 2012

56. Hopf HW, Hunt TK, West JM, Blomquist P, Goodson WH III, Jensen JA, et al: Wound tissue oxygen tension predicts the risk of wound infection in surgical patients. Arch Surg 132:997-1005, 1997

57. Institute for Healthcare Improvement: Reconcile Medications at All Transition Points. (http://www.ihi.org/resources/ Pages/Changes/ReconcileMedicationsatAllTransitionPoints. aspx) [Accessed October 15, 2015]

58. Institute of Medicine: Crossing the Quality Chasm: A New Health System for the 21st Century. Washington, DC: National Academy Press, 2001

59. Institute of Medicine: Preventing Medication Errors. Quality Chasm Series. Washington, DC: National Academies Press, 2006

60. Janssen SJ, Braun Y, Wood KB, Cha TD, Schwab JH: Allogeneic blood transfusions and postoperative infections after lumbar spine surgery. Spine J 15:901-909, 2015

61. Jobe BA, Grasley A, Deveney KE, Deveney CW, Sheppard BC: Clostridium difficile colitis: an increasing hospitalacquired illness. Am J Surg 169:480-483, 1995

62. Kakimaru H, Kono M, Matsusaki M, Iwata A, Uchio Y: Postoperative antimicrobial prophylaxis following spinal decompression surgery: is it necessary? J Orthop Sci 15:305-309, 2010

63. Kalso E, Edwards JE, Moore RA, McQuay HJ: Opioids in chronic non-cancer pain: systematic review of efficacy and safety. Pain 112:372-380, 2004

64. Kanayama M, Hashimoto T, Shigenobu K, Oha F, Togawa D: Effective prevention of surgical site infection using a Centers for Disease Control and Prevention guidelinebased antimicrobial prophylaxis in lumbar spine surgery. J Neurosurg Spine 6:327-329, 2007

65. Kang DG, Holekamp TF, Wagner SC, Lehman RA Jr: Intrasite vancomycin powder for the prevention of surgical site infection in spine surgery: a systematic literature review. Spine J 15:762-770, 2015

66. Kërveshi A, Halili N, Kastrati B, Qosja F, Kabashi S, Muçaj $S$ : Local irrigation of the surgical field with antibiotics in the end of procedure reduces the infection rate in herniated lumbar disc surgery. Mater Sociomed 26:398-400, 2014

67. Khan IU, Janjua MB, Hasan S, Shah S: Surgical site infection in lumbar surgeries, pre and postoperative antibiotics and length of stay: a case study. J Ayub Med Coll Abbottabad 21:135-138, 2009 
68. Kilcup M, Schultz D, Carlson J, Wilson B: Postdischarge pharmacist medication reconciliation: impact on readmission rates and financial savings. J Am Pharm Assoc (2003) 53:78-84, 2013

69. Kim BD, Smith TR, Lim S, Cybulski GR, Kim JY: Predictors of unplanned readmission in patients undergoing lumbar decompression: multi-institutional analysis of 7016 patients. J Neurosurg Spine 20:606-616, 2014

70. Kim MJ, Shim MS, Kim MK, Lee Y, Shin YG, Chung CH, et al: Effect of chronic alcohol ingestion on bone mineral density in males without liver cirrhosis. Korean J Intern Med 18:174-180, 2003

71. Koehler BE, Richter KM, Youngblood L, Cohen BA, Prengler ID, Cheng D, et al: Reduction of 30-day postdischarge hospital readmission or emergency department (ED) visit rates in high-risk elderly medical patients through delivery of a targeted care bundle. J Hosp Med 4:211-218, 2009

72. Kohn LT, Corrigan JM, Donaldson MS (eds): To Err Is Human: Building a Safer Health System. Washington, DC: National Academy Press, 1999

73. Kripalani S, Jackson AT, Schnipper JL, Coleman EA: Promoting effective transitions of care at hospital discharge: a review of key issues for hospitalists. J Hosp Med 2:314 323,2007

74. Lafage V, Smith JS, Bess S, Schwab FJ, Ames CP, Klineberg E, et al: Sagittal spino-pelvic alignment failures following three column thoracic osteotomy for adult spinal deformity. Eur Spine J 21:698-704, 2012

75. Lau HS, Florax C, Porsius AJ, De Boer A: The completeness of medication histories in hospital medical records of patients admitted to general internal medicine wards. Br J Clin Pharmacol 49:597-603, 2000

76. Lawrence JT, London N, Bohlman HH, Chin KR: Preoperative narcotic use as a predictor of clinical outcome: results following anterior cervical arthrodesis. Spine (Phila Pa 1976) 33:2074-2078, 2008

77. Leape LL, Brennan TA, Laird N, Lawthers AG, Localio AR, Barnes BA, et al: The nature of adverse events in hospitalized patients. Results of the Harvard Medical Practice Study II. N Engl J Med 324:377-384, 1991

78. Lee MJ, Cizik AM, Hamilton D, Chapman JR: Predicting medical complications after spine surgery: a validated model using a prospective surgical registry. Spine $\mathbf{J}$ 14:291-299, 2014

79. Lee SE, Kim KT, Park YS, Kim YB: Association between asymptomatic urinary tract infection and postoperative spine infection in elderly women: a retrospective analysis study. $\mathbf{J}$ Korean Neurosurg Soc 47:265-270, 2010

80. Lim S, Edelstein AI, Patel AA, Kim BD, Kim JY: Risk factors for postoperative infections following single level lumbar fusion surgery. Spine (Phila Pa 1976) [epub ahead of print], 2014

81. Marquez-Lara A, Nandyala SV, Fineberg SJ, Singh K: Cerebral vascular accidents after lumbar spine fusion. Spine (Phila Pa 1976) 39:673-677, 2014

82. Marquez-Lara A, Nandyala SV, Sankaranarayanan S, Noureldin M, Singh K: Body mass index as a predictor of complications and mortality after lumbar spine surgery. Spine (Phila Pa 1976) 39:798-804, 2014

83. Masuda K, Chikuda H, Yasunaga H, Hara N, Horiguchi H, Matsuda S, et al: Factors affecting the occurrence of pulmonary embolism after spinal surgery: data from the national administrative database in Japan. Spine J 12:1029-1034, 2012

84. McClendon J Jr, Smith TR, Thompson SE, Sugrue PA, O'Shaughnessy BA, Ondra SL, et al: The impact of body mass index on hospital stay and complications after spinal fusion. Neurosurgery 74:42-50, 2014
85. McDonald M, Grabsch E, Marshall C, Forbes A: Singleversus multiple-dose antimicrobial prophylaxis for major surgery: a systematic review. Aust N Z J Surg 68:388-396, 1998

86. McGirt MJ, Speroff T, Dittus RS, Harrell FE Jr, Asher AL: The National Neurosurgery Quality and Outcomes Database (N2QOD): general overview and pilot-year project description. Neurosurg Focus 34(1):E6, 2013

87. McGregor AH, Probyn K, Cro S, Doré CJ, Burton AK, Balagué $\mathrm{F}$, et al: Rehabilitation following surgery for lumbar spinal stenosis. A Cochrane review. Spine (Phila Pa 1976) 39: 1044-1054, 2014

88. Menendez ME, Ring D, Bateman BT: Preoperative opioid misuse is associated with increased morbidity and mortality after elective orthopaedic surgery. Clin Orthop Relat Res 473:2402-2412, 2015

89. Meyer D, Klarenbeek R, Meyer F: Current concepts in perioperative care for the prevention of deep surgical site infections in elective spinal surgery. Cent Eur Neurosurg 71:117-120, 2010

90. Miller JA, Derakhshan A, Lubelski D, Alvin MD, McGirt MJ, Benzel EC, et al: The impact of preoperative depression on quality of life outcomes after lumbar surgery. Spine $\mathbf{J}$ 15:58-64, 2015

91. Møller AM, Villebro N, Pedersen T, Tønnesen H: Effect of preoperative smoking intervention on postoperative complications: a randomised clinical trial. Lancet 359:114-117, 2002

92. Mueller B, Carreon LY, Glassman SD: Comparison of the EuroQOL-5D with the Oswestry Disability Index, back and leg pain scores in patients with degenerative lumbar spine pathology. Spine (Phila Pa 1976) 38:757-761, 2013

93. Namias N, Harvill S, Ball S, McKenney MG, Salomone JP, Civetta JM: Cost and morbidity associated with antibiotic prophylaxis in the ICU. J Am Coll Surg 188:225-230, 1999

94. Nath B, Li Y, Carroll JE, Szabo G, Tseng JF, Shah SA: Alcohol exposure as a risk factor for adverse outcomes in elective surgery. J Gastrointest Surg 14:1732-1741, 2010

95. National Institute of Health: Helping Patients Who Drink Too Much: A Clinical Approach. (http://pubs.niaaa.nih. gov/publications/Practitioner/CliniciansGuide2005/clinicians_guide.htm) [Accessed October 15, 2015]

96. National Quality Forum: Preferred Practices and Performance Measures for Measuring and Reporting Care Coordination: A Consensus Report. Washington, DC: National Quality Forum, 2010

97. Nemoto Y, Matsuzaki H, Tokuhasi Y, Okawa A, Uematu Y, Nishimura T, et al: Histological changes in intervertebral discs after smoking and cessation: experimental study using a rat passive smoking model. J Orthop Sci 11:191-197, 2006

98. Núñez-Pereira S, Rodríguez-Pardo D, Pellisé F, Pigrau C, Bagó J, Villanueva C, et al: Postoperative urinary tract infection and surgical site infection in instrumented spinal surgery: is there a link? Clin Microbiol Infect 20:768-773, 2014

99. Ogden CL, Carroll MD, Kit BK, Flegal KM: Prevalence of obesity among adults: United States, 2011-2012. NCHS Data Brief (131): 1-8, 2013

100. Oosterhuis T, Costa LO, Maher CG, de Vet HC, van Tulder MW, Ostelo RW: Rehabilitation after lumbar disc surgery. Cochrane Database Syst Rev 3:CD003007, 2014

101. Oppedal K, Møller AM, Pedersen B, Tønnesen H: Preoperative alcohol cessation prior to elective surgery. Cochrane Database Syst Rev 7:CD008343, 2012

102. Park Y, Lee SB, Seok SO, Jo BW, Ha JW: Perioperative surgical complications and learning curve associated with minimally invasive transforaminal lumbar interbody fusion: 
a single-institute experience. Clin Orthop Surg 7:91-96, 2015

103. Parker SL, Adogwa O, Mendenhall SK, Shau DN, Anderson WN, Cheng JS, et al: Determination of minimum clinically important difference (MCID) in pain, disability, and quality of life after revision fusion for symptomatic pseudoarthrosis. Spine J 12: 1122-1128, 2012

104. Parker SL, Asher AL: Registry science has identified opportunities for improvement in spine care. AANS Neurosurgeon 24 (http://v1archives.aansneurosurgeon.org/ features/registry-science-has-identified-opportunities-forimprovement-in-spine-care/) [Accessed October 15, 2015]

105. Parker SL, Godil SS, Zuckerman SL, Mendenhall SK, Devin CJ, McGirt MJ: Extent of preoperative depression is associated with return to work after lumbar fusion for spondylolisthesis. World Neurosurg 83:608-613, 2015

106. Parker SL, McGirt MJ: Determination of the minimum improvement in pain, disability, and health state associated with cost-effectiveness: introduction of the concept of minimum cost-effective difference. Neurosurgery 76 (Suppl 1):S64-S70, 2015

107. Parker SL, Mendenhall SK, Shau D, Adogwa O, Cheng JS, Anderson WN, et al: Determination of minimum clinically important difference in pain, disability, and quality of life after extension of fusion for adjacent-segment disease. $\mathbf{J}$ Neurosurg Spine 16:61-67, 2012

108. Parker SL, Mendenhall SK, Shau DN, Adogwa O, Anderson WN, Devin CJ, et al: Minimum clinically important difference in pain, disability, and quality of life after neural decompression and fusion for same-level recurrent lumbar stenosis: understanding clinical versus statistical significance. J Neurosurg Spine 16:471-478, 2012

109. Pasulka PS, Bistrian BR, Benotti PN, Blackburn GL: The risks of surgery in obese patients. Ann Intern Med 104:540-546, 1986

110. Pierson DJ: Pathophysiology and clinical effects of chronic hypoxia. Respir Care 45:39-53, 2000

111. Pocock NA, Eisman JA, Kelly PJ, Sambrook PN, Yeates MG: Effects of tobacco use on axial and appendicular bone mineral density. Bone 10:329-331, 1989

112. Pronovost P, Weast B, Schwarz M, Wyskiel RM, Prow D, Milanovich SN, et al: Medication reconciliation: a practical tool to reduce the risk of medication errors. J Crit Care 18:201-205, 2003

113. Pugely AJ, Martin CT, Gao Y, Mendoza-Lattes S: Causes and risk factors for 30-day unplanned readmissions after lumbar spine surgery. Spine (Phila Pa 1976) 39:761-768, 2014

114. Ran B, Li Q, Chen J, Chen Z, Niu Y, Shi Z, et al: Association between overweight or obesity and lumbar disc diseases: a meta-analysis. J Spinal Disord Tech [epub ahead of print], 2014

115. Rihn JA, Kurd M, Hilibrand AS, Lurie J, Zhao W, Albert $\mathrm{T}$, et al: The influence of obesity on the outcome of treatment of lumbar disc herniation: analysis of the Spine Patient Outcomes Research Trial (SPORT). J Bone Joint Surg Am 95: $1-8,2013$

116. Rolston JD, Han SJ, Lau CY, Berger MS, Parsa AT: Frequency and predictors of complications in neurological surgery: national trends from 2006 to 2011 . J Neurosurg 120:736-745, 2014

117. Rönnberg K, Lind B, Zoëga B, Halldin K, Gellerstedt M, Brisby H: Patients' satisfaction with provided care/information and expectations on clinical outcome after lumbar disc herniation surgery. Spine (Phila Pa 1976) 32:256-261, 2007

118. Sandén B, Försth P, Michaëlsson K: Smokers show less improvement than nonsmokers two years after surgery for lumbar spinal stenosis: a study of 4555 patients from the
Swedish spine register. Spine (Phila Pa 1976) 36:10591064, 2011

119. Sato S, Yagi M, Machida M, Yasuda A, Konomi T, Miyake A, et al: Reoperation rate and risk factors of elective spinal surgery for degenerative spondylolisthesis: minimum 5-year follow-up. Spine J 15: 1536-1544, 2015

120. Schairer WW, Carrer A, Sing DC, Chou D, Mummaneni PV, Hu SS, et al: Hospital readmission rates after surgical treatment of primary and metastatic tumors of the spine. Spine (Phila Pa 1976) 39:1801-1808, 2014

121. Scheer JK, Mundis GM, Klineberg E, Hart RA, Deviren V, Burton DC, et al: Recovery following adult spinal deformity surgery: the effect of complications and reoperation in 149 patients with 2-year follow-up. Eur Spine J [epub ahead of print], 2015

122. Scheer JK, Smith JS, Clark AJ, Lafage V, Kim HJ, Rolston JD, et al: Comprehensive study of back and leg pain improvements after adult spinal deformity surgery: analysis of 421 patients with 2-year follow-up and of the impact of the surgery on treatment satisfaction. J Neurosurg Spine 22:540-553, 2015

123. Scheer JK, Tang JA, Smith JS, Klineberg E, Hart RA, Mundis GM Jr, et al: Reoperation rates and impact on outcome in a large, prospective, multicenter, adult spinal deformity database: clinical article. J Neurosurg Spine 19:464-470, 2013

124. Schoenfeld AJ, Harris MB, Liu H, Birkmeyer JD: Variations in Medicare payments for episodes of spine surgery. Spine J 14:2793-2798, 2014

125. Schoenfeld AJ, Herzog JP, Dunn JC, Bader JO, Belmont PJ Jr: Patient-based and surgical characteristics associated with the acute development of deep venous thrombosis and pulmonary embolism after spine surgery. Spine (Phila Pa 1976) 38: 1892-1898, 2013

126. Schoenfeld AJ, Ochoa LM, Bader JO, Belmont PJ Jr: Risk factors for immediate postoperative complications and mortality following spine surgery: a study of 3475 patients from the National Surgical Quality Improvement Program. J Bone Joint Surg Am 93:1577-1582, 2011

127. Schulte LM, O'Brien JR, Bean MC, Pierce TP, Yu WD, Meals C: Deep vein thrombosis and pulmonary embolism after spine surgery: incidence and patient risk factors. Am J Orthop 42:267-270, 2013

128. Schwab FJ, Blondel B, Bess S, Hostin R, Shaffrey CI, Smith JS, et al: Radiographical spinopelvic parameters and disability in the setting of adult spinal deformity: a prospective multicenter analysis. Spine (Phila Pa 1976) 38:E803E812, 2013

129. Seicean A, Seicean S, Alan N, Schiltz NK, Rosenbaum BP, Jones PK, et al: Effect of smoking on the perioperative outcomes of patients who undergo elective spine surgery. Spine (Phila Pa 1976) 38:1294-1302, 2013

130. Sepucha KR, Levin CA, Uzogara EE, Barry MJ, O'Connor AM, Mulley AG: Developing instruments to measure the quality of decisions: early results for a set of symptomdriven decisions. Patient Educ Couns 73:504-510, 2008

131. Shen Y, Silverstein JC, Roth S: In-hospital complications and mortality after elective spinal fusion surgery in the united states: a study of the nationwide inpatient sample from 2001 to 2005. J Neurosurg Anesthesiol 21:21-30, 2009

132. Silcox DH III, Daftari T, Boden SD, Schimandle JH, Hutton WC, Whitesides TE Jr: The effect of nicotine on spinal fusion. Spine (Phila Pa 1976) 20:1549-1553, 1995

133. Sinikallio S, Aalto T, Airaksinen O, Herno A, Kröger H, Viinamäki H: Depressive burden in the preoperative and early recovery phase predicts poorer surgery outcome among lumbar spinal stenosis patients: a one-year prospective follow-up study. Spine (Phila Pa 1976) 34:2573-2578, 2009 
134. Sinikallio S, Aalto T, Airaksinen O, Lehto SM, Kröger H, Viinamäki H: Depression is associated with a poorer outcome of lumbar spinal stenosis surgery: a two-year prospective follow-up study. Spine (Phila Pa 1976) 36:677-682, 2011

135. Skovrlj B, Gilligan J, Cutler HS, Qureshi SA: Minimally invasive procedures on the lumbar spine. World J Clin Cases 3:1-9, 2015

136. Smith JS, Klineberg E, Schwab F, Shaffrey CI, Moal B, Ames CP, et al: Change in classification grade by the SRSSchwab Adult Spinal Deformity Classification predicts impact on health-related quality of life measures: prospective analysis of operative and nonoperative treatment. Spine (Phila Pa 1976) 38: 1663-1671, 2013

137. Smith JS, Shaffrey E, Klineberg E, Shaffrey CI, Lafage V, Schwab FJ, et al: Prospective multicenter assessment of risk factors for rod fracture following surgery for adult spinal deformity. J Neurosurg Spine 21:994-1003, 2014

138. Soroceanu A, Ching A, Abdu W, McGuire K: Relationship between preoperative expectations, satisfaction, and functional outcomes in patients undergoing lumbar and cervical spine surgery: a multicenter study. Spine (Phila Pa 1976) 37:E103-E108, 2012

139. Stafford L, Stafford A, Hughes J, Angley M, Bereznicki L, Peterson G: Drug-related problems identified in postdischarge medication reviews for patients taking warfarin. Int J Clin Pharm 33:621-626, 2011

140. Stey AM, Russell MM, Ko CY, Sacks GD, Dawes AJ, Gibbons MM: Clinical registries and quality measurement in surgery: a systematic review. Surgery 157:381-395, 2015

141. Street JT, Lenehan BJ, DiPaola CP, Boyd MD, Kwon BK, Paquette SJ, et al: Morbidity and mortality of major adult spinal surgery. A prospective cohort analysis of 942 consecutive patients. Spine J 12:22-34, 2012

142. Tam VC, Knowles SR, Cornish PL, Fine N, Marchesano R, Etchells EE: Frequency, type and clinical importance of medication history errors at admission to hospital: a systematic review. CMAJ 173:510-515, 2005

143. Tominaga H, Setoguchi T, Tanabe F, Kawamura I, Tsuneyoshi Y, Kawabata N, et al: Risk factors for venous thromboembolism after spine surgery. Medicine (Baltimore) 94:e466, 2015

144. Tomov M, Mitsunaga L, Durbin-Johnson B, Nallur D, Roberto R: Reducing surgical site infection in spinal surgery with betadine irrigation and intrawound vancomycin powder. Spine (Phila Pa 1976) 40:491-499, 2015

145. Tønnesen H: Alcohol abuse and postoperative morbidity. Dan Med Bull 50:139-160, 2003

146. Tonnesen H, Kehlet H: Preoperative alcoholism and postoperative morbidity. Br J Surg 86:869-874, 1999

147. Tønnesen H, Petersen KR, Højgaard L, Stokholm KH, Nielsen HJ, Knigge U, et al: Postoperative morbidity among symptom-free alcohol misusers. Lancet 340:334-337, 1992

148. Van Boxem K, Cheng J, Patijn J, van Kleef M, Lataster A, Mekhail N, et al: 11. Lumbosacral radicular pain. Pain Pract 10:339-358, 2010

149. Wang MC, Shivakoti M, Sparapani RA, Guo C, Laud PW, Nattinger AB: Thirty-day readmissions after elective spine surgery for degenerative conditions among US Medicare beneficiaries. Spine J 12:902-911, 2012

150. Weinstein JN, Lurie JD, Tosteson TD, Zhao W, Blood EA, Tosteson ANA, et al: Surgical compared with nonoperative treatment for lumbar degenerative spondylolisthesis. Fouryear results in the Spine Patient Outcomes Research Trial (SPORT) randomized and observational cohorts. J Bone Joint Surg Am 91:1295-1304, 2009

151. Weinstein JN, Tosteson TD, Lurie JD, Tosteson A, Blood E, Herkowitz H, et al: Surgical versus nonoperative treat- ment for lumbar spinal stenosis four-year results of the Spine Patient Outcomes Research Trial. Spine (Phila Pa 1976) 35: 1329-1338, 2010

152. Weiss AJ, Elixhauser A, Andrews RM: Characteristics of Operating Room Procedures in U.S. Hospitals, 2011. HCUP Statistical Brief 170. Washington, DC: Agency for Healthcare Research and Quality, 2014

153. Wenger NS, Young R: Working Paper: Quality Indicators of Continuity and Coordination of Care for Vulnerable Elder Persons. Santa Monica, CA: Rand Corporation, 2004

154. Williams EI, Fitton F: General practitioner response to elderly patients discharged from hospital. BMJ 300:159 161,1990

155. Wong AP, Smith ZA, Nixon AT, Lawton CD, Dahdaleh NS, Wong RH, et al: Intraoperative and perioperative complications in minimally invasive transforaminal lumbar interbody fusion: a review of 513 patients. J Neurosurg Spine 22:487-495, 2015

156. Xing D, Ma JX, Ma XL, Song DH, Wang J, Chen Y, et al: A methodological, systematic review of evidence-based independent risk factors for surgical site infections after spinal surgery. Eur Spine J 22:605-615, 2013

157. Yamashita K, Hayashi J, Ohzono K, Hiroshima K: Correlation of patient satisfaction with symptom severity and walking ability after surgical treatment for degenerative lumbar spinal stenosis. Spine (Phila Pa 1976) 28:24772481, 2003

158. Yamashita K, Ohzono K, Hiroshima K: Patient satisfaction as an outcome measure after surgical treatment for lumbar spinal stenosis: testing the validity and discriminative ability in terms of symptoms and functional status. Spine (Phila Pa 1976) 31:2602-2608, 2006

159. Yoshioka K, Murakami H, Demura S, Kato S, Tsuchiya $\mathrm{H}$ : Prevalence and risk factors for development of venous thromboembolism after degenerative spinal surgery. Spine (Phila Pa 1976) 40:E301-E306, 2015

160. Young AK, Young BK, Riley LH III, Skolasky RL: Assessment of presurgical psychological screening in patients undergoing spine surgery: use and clinical impact. J Spinal Disord Tech 27:76-79, 2014

\section{Disclosures}

Dr. Knightly reports being on the Board of Directors of NeuroPoint Alliance.

\section{Author Contributions}

Conception and design: Asher, Parker, McGirt, Devin. Acquisition of data: Bekelis. Analysis and interpretation of data: Asher. Drafting the article: Asher, Parker, Groman. Critically revising the article: McGirt, Bekelis, Holland, Davies, Devin, Atkins, Knightly, Zyung. Reviewed submitted version of manuscript: Asher, Parker, Davies, Devin.

\section{Supplemental Information}

\section{Online Content}

Supplemental material is available online.

Appendix 1. http://thejns.org/doi/suppl/10.3171/2015.9.

\section{FOCUS15355.}

\section{Correspondence}

Anthony L. Asher, Carolina Neurosurgery \& Spine Associates, 225 Baldwin Rd., Charlotte, NC 28204. email: tony.asher@cnsa. com. 